Gut, 1969, 10, 838-841

\title{
The high incidence of intestinal volvulus in $\operatorname{Iran}^{1}$
}

\author{
FARROKH SAIDI \\ From the Department of Surgery, Pahlavi University, Shiraz, Iran
}

SUMMARY The incidence of intestinal volvulus gleaned from the world's medical literature spread over the past seven decades supports thecontention that this boweldisorder has distinct geographical predilections. Sigmoid volvulus, invariably superimposed upon a redundancy of this part of the bowel, probably results from a functional disturbance of the colon mediated perhaps by a high-residue vegetable diet. The same factors appear to hold for small bowel volvulus, though caecal volvulus occurs strictly on the basis of preexisting anatomical abnormalities.

The chapter dealing with intestinal volvulus in standard medical and surgical textbooks is invariably prefaced with a reference to the high incidence of volvulus of the sigmoid colon in east European, Russian, or Nordic countries at the turn of the century. This idea has so often been repeated that it has become an accepted surgical-pathological truth. The evidence, in fact, is based on relatively few, isolated reports from Scandinavia, Germany, and Russia in the early nineteen hundreds (Samson, 1889; Obalinski, 1894; Edgren, 1901 ; Spassokukozki, 1909; Philipowicz, 1924; Adzarow, Stopinow, Subotic, Petrow, Gjurgjewic, and Lilic, 1924; Perlmann, 1925, Kusnezoff and Poljenoff, 1926). Subsequently Gerwig in 1950, studying the incidence of sigmoid volvulus in the United States of America, alluded to the comparatively higher frequency of this condition in eastern Europe compared with that in America, namely, $7 \%$ versus $4 \%$ of obstructions, and perpetuated in the surgical literature the concept of a geographical disparity in the frequency of intestinal volvulus.

No doubt socioeconomic factors, together with the overall pattern of large bowel disease in eastern Europe and the Scandinavian countries, have changed over the past decades. It would be difficult to reconstruct former conditions in these areas to verify what may in fact have been a correct observation. More recent reports do not indicate a higher than usual incidence of volvulus of the sigmoid in these countries (Sundell, 1961). The available historical evidence must be taken accordingly for what it is worth.

Clinical observations over the past few years in

1 Presented at a meeting of the British Society of Gastroenterology, London, November 1968. south Iran seem to indicate that intestinal volvulus can indeed have a geographically higher incidence in some parts of the world as compared with others (Table I). Curiously enough, this discrepancy in geo-

TABLE I

WORLD INCIDENCE OF INTESTINAL VOLVULUS

\begin{tabular}{|c|c|c|c|c|c|}
\hline Author & Place & $\begin{array}{l}\text { No. of } \\
\text { Obstruc- } \\
\text { tions }\end{array}$ & $\begin{array}{l}\text { Sigmoid } \\
\text { Colon }\end{array}$ & $\begin{array}{l}\text { Small } \\
\text { Bowel }\end{array}$ & Caecum \\
\hline $\begin{array}{l}\text { Vick (1932) } \\
\text { Gibson (1900) } \\
\text { Sweet (1935) } \\
\text { Braun and Wortmann } \\
\text { (1924) }\end{array}$ & $\begin{array}{l}\text { London } \\
\text { New York } \\
\text { Boston } \\
\text { Berlin }\end{array}$ & $\begin{array}{r}6,892 \\
1,000 \\
520 \\
750\end{array}$ & $\begin{array}{l}0.86 \\
5.8 \\
1.92 \\
4.1\end{array}$ & $\begin{array}{l}1.2 \\
3.6 \\
6.92 \\
7.4\end{array}$ & $\begin{array}{l}0.5 \\
1.5 \\
1.15 \\
0.93\end{array}$ \\
\hline $\begin{array}{l}\text { Spassokukozky (1909) } \\
\text { Hall-Craggs (1960) }\end{array}$ & $\begin{array}{l}\text { Smolensk } \\
\text { East } \\
\text { Africa }\end{array}$ & $\begin{array}{r}96 \\
1,230\end{array}$ & $\begin{array}{r}18.7 \\
8.4\end{array}$ & $\begin{array}{r}28 \cdot 1 \\
1.7\end{array}$ & $\begin{array}{l}1.0 \\
0.05\end{array}$ \\
\hline $\begin{array}{l}\text { Agarwal and Singh } \\
(1960)\end{array}$ & $\begin{array}{l}\text { Agra, } \\
\text { India }\end{array}$ & 92 & 6.5 & $5 \cdot 2$ & 1.0 \\
\hline Sankaran (1962) & $\begin{array}{l}\text { South } \\
\text { India }\end{array}$ & 225 & 11.8 & - & - \\
\hline Scott (1964) & $\begin{array}{l}\text { North } \\
\text { Iran }\end{array}$ & 44 & 38.0 & - & - \\
\hline Saidi (1969) & $\begin{array}{l}\text { South } \\
\text { Iran }\end{array}$ & 286 & 13.6 & $22 \cdot 7$ & 5.7 \\
\hline
\end{tabular}

graphical frequency seems to hold true for volvulus of practically all portions of the gut. This report is based on clinical experience, extending over a sixyear period, at a community university hospital in Shiraz, Iran.

Between August 1962 and August 1968, 286 adult patients with acute obstruction of the large and small bowel were admitted to Saadi Hospital of Pahlavi University School of Medicine. The cause of obstruction in $120(42 \%)$ patients was an occlusive twist of the bowel. In $32.5 \%$ of these cases the sigmoid colon was involved, $54.2 \%$ had torsion of the small bowel, and in $13.3 \%$ the caecum was primarily affected. 


\section{SIGMOID VOLVULUS}

A total of 37 patients had 39 separate episodes of colonic volvulus. This group consisted of 34 men and three women, their age range being 19 to 85 years (average age 53 years).

Eight patients gave a history of previous episodes of recurring abdominal pain. The diagnosis was readily made in almost all instances on well established clinical grounds. Detorsion was attempted by inserting a rectal tube under sigmoidoscopic control in most cases when strangulation was not suspected clinically, and the results were invariably successful. Fourteen patients had gangrene of the sigmoid colon at laparotomy. Treatment consisted of expeditious resection and colostomy. Nevertheless, the mortality in this particular group was $57 \%$ compared with the mortality in those in whom the bowel was viable, $17 \%$, giving an overall mortality of $33 \%$ for all cases of sigmoid volvulus.

Experience seems to indicate that once volvulus occurs and is relieved either by inserting a rectal tube or at laparotomy, subsequent resection of the redundant bowel is mandatory, as recurrence of the torsion is the rule rather than the exception. This appears to occur within an average period of six weeks. Two patients in this series in whom, for one reason or another, resection was not carried out within this period, had a recurrence of the volvulus with gangrene within two weeks and six weeks, respectively. Both died despite early surgical intervention.

Redundancy of the sigmoid colon, a prerequisite for volvulus, has been attributed to vitamin B deficiency (Raia, 1955) and lead poisoning (Berger and Lundberg, 1951) and is apparently not too rare a finding among inmates of mental institutions (Bates and Glancy, 1960). The most common underlying factor in this series of patients, however, appears to have been dietary and possibly abnormal bowel habits. The diet of the rural population of south Iran consists for the most part of vegetable matter, and the storage function of the sigmoid colon and rectum may be unduly taxed by such a poorly absorbed, high-residue diet. But the exact manner in which this stagnation process leads to an abnormal lengthening and dilatation of the bowel lumen is not at all clear and bears further investigation. The relationship in any case does not seem to be a direct or simple one, however. Volvulus of the sigmoid colon has been reported in children (Allen and Nordstrom, 1964) and this condition was seen in an 8-year-old boy in Shiraz. Accordingly factors and forces other than diet must exist which can lead to a redundancy of the sigmoid colon. In the absence of structural disorders of the autonomic nervous system of the lower intestinal tract, verified by serial histological sections, the condition is most probably due to chronic functional disturbances of the lower colon and rectum.

\section{SMALL BOWEL VOLVULUS}

Small bowel volvulus was encountered even more often than sigmoid volvulus during the study period. This condition is relatively rare in Europe and North America (Gibson, 1900; Sweet, 1935; McKechnie and Priestley, 1936; Moretz and Morton, 1950; Talbot, 1960). This particular group of 65 patients consisted of 61 men and four women, with an age range of 17 to 70 years and an average age of 31 years.

Why, under normal circumstances, some 20 feet of small intestine crammed into the peritoneal cavity, and attached to the posterior abdominal wall by a relatively short mesenteric root, does not twist around the mesentery under normal circumstances is intriguing. Nevertheless, it does not seem to do so unless there are some associated precipitating factors or forces. In 17 patients in this group some of the precipitating anatomical factors were found at operation to be bands and adhesions in five patients, a Meckel's diverticulum in three, and an associated volvulus of the large bowel in nine patients. This subgroup has been labelled as having 'secondary small bowel volvulus', as distinct from a larger subgroup of 48 patients in whom no precipitating factor was discovered and accordingly were said to have 'primary small bowel volvulus'.

A correct preoperative diagnosis of small bowel volvulus was made less often than was the case for large bowel volvulus. However, since early operative intervention in preference to a more conservative nonoperative approach is the accepted mode of management of acute small bowel obstruction at this hospital, the diagnosis of small bowel obstruction was accurately established in all cases at operation or at necropsy.

The torsion had invariably involved the terminal bowel, and the rotation was noted to be clockwise when the direction of the turning was specifically looked for. The involved portion of the mesentery was oedematous and thickened and quite often presented discrete patches of subserosal haemorrhage on both sides (Fig. 1).

Surgical treatment consisted of resection of the gangrenous portion of the bowel followed by end-toend anastomosis. If strangulation had not occurred, the bowel was simply untwisted and restored to the abdomen with no attempt being made at fixation in any manner. Volvulus has not recurred in the small group of patients followed up so far. But the overall 


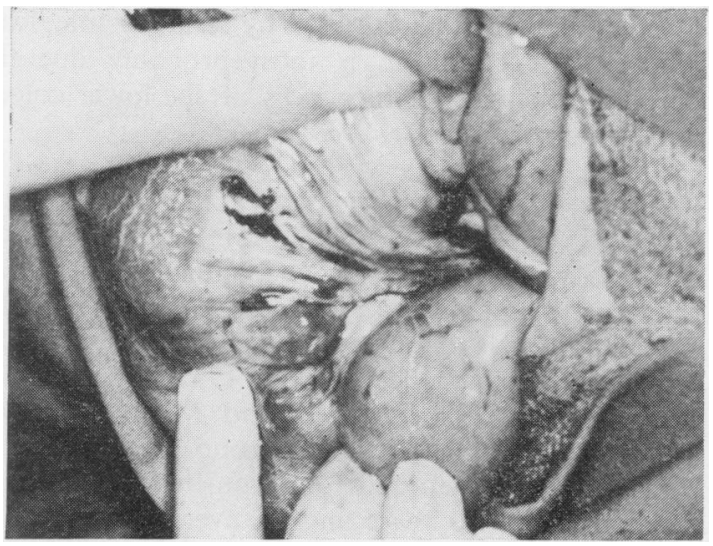

FIG. 1. Subserosal haemorrhagic spots on the mesentary of twisted bowel.

early postoperative mortality $(28 \%)$ has been high in this group.

No ready explanation is available for the high frequency of primary small bowel volvulus in southern Iran. The question of racially determined anatomical variation in this group of patients, setting the stage for primary volvulus of the small bowel, has been raised. In six of these patients the bowel dimensions were carefully measured and compared with those in 100 necropsy cases dying of extraabdominal conditions (Table II). The length of the mesenteric root from the ligament of Treitz to the ileocaecal valve was somewhat shorter on average in the volvulus cases, and the breadth of the mesentery somewhat larger than in the control group. But these differences were not sufficiently great to have mattered much. The overall length of bowel in the control group was significantly greater, but some of this discrepancy can be attributed to postmortem changes of bowel length in the control group.

TABLE II

DIMENSIONS OF THE SMALL BOWEL IN CASES OF INTESTINAL VOLVULUS AND CONTROLS MEASURED AT NECROPSY

\begin{tabular}{lll} 
Measurement $(\mathrm{cm})$ & $\begin{array}{l}\text { Intestinal } \\
\text { Volvulus }\end{array}$ & Control \\
\hline Average length of mesenteric root & $13 \cdot 4$ & $14 \cdot 8$ \\
Average breadth of mesentary & 22 & $18 \cdot 7$ \\
Average length of jejunum and ileum & 499 & 622
\end{tabular}

Exonerating purely anatomical factors in the primary volvulus cases and focusing more on the functional aspects of the bowel, it appeared that there was a distinct, albeit a gross, relationship between the relatively high incidence of volvulus of the small bowel in the population at risk and dietary habits. The custom among farmers of south Iran is to ingest relatively large amounts of bulky vegetable food twice daily with a long period of fasting in between. Presumably, the resulting hypermobility and hypermotility of the small intestine and the sudden filling of the proximal small bowel can displace the more distal empty small intestine out of the pelvis in a rotatory manner and initiate a clockwise torsion around the mesentery (Vaez-Zadeh, Dutz, and Nowrooz-Zadeh, 1969). Quite a number of patients in this series had in fact experienced episodes of abdominal pain in the past, and in some of them the acute onset of illness could be roughly timed to having occurred shortly after eating a bulky meal on an empty stomach. A similar situation has been observed among patients in Germany who, in the immediate postwar period when food was scarce, ate large amounts of food after long periods of relative deprivation.

\section{CAECAL VOLVULUS}

There were 16 patients in this group, nine men and seven women, with an average age of 39 , and a range of 25 to 66 years. There was a nearly equal incidence of viable and gangrenous bowel in this group, the overall mortality being $29 \%$.

In all these cases the caecum was free and highly mobile, with no attachment to the posterior abdominal wall. Why this particular anatomical maldevelopment should be relatively common in this particular population is not at all clear. Certainly, neither bowel length as such nor peculiar dietary habits can be invoked in explaining the occurrence of this type of bowel pathology. The condition is a clinical rarity in other parts of the world, presenting in no more than about $5 \%$ of all cases of volvulus reported in the western surgical literature (Donhauser and Atwell, 1949; Sweet, 1935).

\section{COMBINED VOLVULUS}

As occlusive torsion of various portions of the gut is on the whole quite common in this part of the world, it was not surprising that simultaneous volvulus of different portions of the bowel would also be encountered sooner or later. In fact nine patients, seven men and two women, with an average age of 47 and a range of 30 to 60 years, presented the clinical picture of combined large and small bowel volvulus during the study period.

All of these patients appeared to have a preexisting redundant and mobile sigmoid colon which had probably induced torsion of the small bowel. Interestingly enough the colon by itself was never gangrenous, the small bowel alone was infarcted in two cases, and in the remaining six both large and small 
bowel were gangrenous. One of the female patients in this last category was six months pregnant.

A variant of combined volvulus of the large and small bowel is the simultaneous volvulus of the small intestine, sigmoid colon, and caecum. This was observed in a 40-year-old man in whom all the involved and gangrenous portions of the bowel were successfully resected. The operative appearance of the bowel in combined volvulus can be most bizarre and perplexing, and has the rightful appellation of the 'knotted bowel' syndrome (Kallio, 1932).

\section{REFERENCES}

Adzarow, Stopinow, Subotic, Petrow, Gjurgjewic, and Lilic (1924) Quoted by Braun, W., and Wortmann, W. (1924). Der Darmverschluss und die sonstigen Wegstorungen des Darmes, Springer, Berlin.

Agarwal, S. L., and Singh, R. P. (1960.) A review of Intestinal Obstruction. Int. surg. Dis., 46, 113-117.

Allen, R. P., and Nordstrom, J. E. (1964). Volvulus of the sigmoid colon in children. Amer. J. Roentgenol., 91, 690-693.

Bates, T. J. N., and Glancy, L. J. (1960). Volvulus of the colon in the demented patient. J. ment. Sci., 106, 1115-1119.

Berger, K. E., and Lundberg, E. A. (1951). Intestinal volvulus precipitated by lead poisoning: report of five cases. Amer. med. Ass., 147, 13-16.

Braun, W., and Wortmann, W. (1924). Der Darmverschluss und die sonstigen Wegstorungen des Darmes. Springer, Berlin.

Donhauser, J. L., and Atwell, S. (1949). Volvulus of the cecum. Arch. Surg., 58, 129-148.

Edgren, K. (1901). Volvulus Flexurae Sigmoideae. Jyvaeskylae, Helsingfors, Finland.

Gerwig, W. H., Jr (1950). Volvulus of the colon. Arch. Surg., 60, $721-742$.

Gibson, C. L. (1900). A study of 1,000 operations for acute intestinal obstruction and gangrenous hernia. Ann. Surg., 32, 486-514 and 676-737.

Hall-Craggs, E. C. B. (1960). Sigmoid volvulus in an African population. Brit. Med. J., 1015-1017.

Kallio, K. E. (1932). Die Knotenbildungen des Darmes. Acta chir. scand., suppl. 21.

Kusnezoff and Poljenoff (1926). Quoted by Fernström, B. (1926). Volvulus of sigmoid flexure. Ibid, 61, 220.

McKechnie, R. E., and Priestley, J. T. (1936). Volvulus of small intestine: A report of 37 cases. Amer. J. Surg., 34, 286-291.

Moretz, W. H., and Morton, J. T. (1950). Acute volvulus of small intestine: Analysis of 36 cases. Ann. Surg., 132, 899-912.

Obalinski, A. (1894). Ueber Laparatomie bei innerem Darmverschluss auf Grund eigener 110 Fälle. Arch. klin. Chir., 48, 1-53.

Perlmann, J. (1925). Klinische Beiträge zur Pathologie und chirurgischen Behandlung des Darmverschlusses. Ibid, 137, 245-264.

Philipowicz (1924). Quoted by Braun, W., and Wortmann, W. (1924). Der Darmverschluss und die sonstigen Wegstorungen des Darmes. Springer, Berlin.

Raia, A. (1955). Pathogenesis and treatment of acquired megacolon. Surg. Gynec. Obstet., 101, 69-79. Cited by Wangensteen, O. H. (1955).

Samson, V. (1889). In Intestinal Obstructions 3rd ed., p. 661. Thomas, Springfield, Ill., 1955. Wangensteen, O. H. (1955).

Sankaran, V. (1962). Volvulus in South India. Indian J. Surg., 24, 784.

Scott, G. W. (1964). Volvulus of the sigmoid flexure, Dis. Colon Rect., 8, 30-34.

Spassokukozki, S. I. (1909). Volvulus intestinorum als Krankheit des hungernden Menschen. Zbl. Chir. (Abstr.), 36, 1563.

Sundell, B. (1961). Volvulus of the intestinal loop: report of 50 cases. Ann. Chir. Gynaec. Fenn., 50, 388-395.

Sweet, R. H. (1935). Volvulus of the cecum, acute and chronic, with reports of eight cases. New Engl. J. Med., 213, 287-293.

Talbot, C. H. (1960). Volvulus of the small intestine in adults. Gut, $1,76-80$.

Vaez-Zadøh, K. Dutz, W., and Nowrooz-Zadeh, M. (1969). Volvulus of the small intestine in adults: a study of predisposing factors. Ann. Surg., 169, 265-271.

Vick, R. M. (1932). Statistics of acute intestinal obstruction, Brit. Med. J., 540-548. 